\title{
Model for identification of correct positioning of parts in a pick and place system
}

\section{Modelo para la identificación del posicionamiento correcto de las piezas en un sistema de selección y colocación}

CAMPAS-BUITIMEA, Julio†*，GONZÁLEZ-LÓPEZ， Samuel， MEDINA-MUÑOZ， Luis and RODRÍGUEZ-ESPINOZA, Indelfonso

\author{
Instituto Tecnológico de Nogales / TECNM -Departamento de Posgrdo e Investigación \\ ID $1^{\text {st }}$ Author: Juan Julio Cesar, Campas-Buitimea / ORC ID: 0000-0003-1190-3929, arXiv Author ID: juliokmpas, CVU \\ CONACYT ID: 990217
}

ID $1^{\text {st }}$ Coauthor: Samuel, González-López / ORC ID: 0000-0002-1511-1227, Researcher ID Thomson: N-6460-2018, CVU CONACYT ID: 345102 ID $2^{\text {nd }}$ Coauthor: Luis Arturo, Medina-Muñoz / ORC ID: 0000-0001-9598-1451, Researcher ID Thomson: H-4735-2018, CVU
CONACYT ID: 454558

ID $3^{\text {rd }}$ Coauthor: Indelfonso, Rodriguez-Espinoza / ORC ID: 0000-0001-6405-9886, Researcher ID Thomson: H-5383-2018, CVU CONACYT ID: 346230

\begin{abstract}
This article investigates the use of automatic learning classification techniques applied to the task of recognizing the correct shape and color of pieces in a connector using neural networks. The system presented here shows that you can use a set of features extracted from the side view of the piece to recognize the shape of the piece and the color. The proposed model is based on two stages, one performs detection and the other is for recognition. In the first stage, color segmentation algorithms have been tested. In the second stage, a method of extracting personalized features in a color recognition approach is used. Finally, the use of a multilayer artificial neural network (ANN) is proposed to recognize and interpret the different possible shapes and colors with which the pieces can come.
\end{abstract}

Artificial neural network, Algorithms, Color segmentation, Feature extraction

\begin{abstract}
Resumen
Este artículo investiga el uso de técnicas de clasificación de aprendizaje automático aplicadas a la tarea de reconocer la correcta forma y color de piezas en un conector utilizando redes neuronales. El sistema presentado aquí demuestra que se puede utilizar un conjunto de características extraídas de la vista lateral de la pieza para reconocer la forma de la pieza y el color. El modelo propuesto se basa en dos etapas, una realiza la detección y la otra es para reconocimiento. En la primera etapa, se han probado algoritmos de segmentación de color. En la segunda etapa, se utiliza un método de extracción de características personalizadas en un enfoque de reconocimiento de color. Finalmente, se propone el uso de una red neuronal artificial multicapa (ANN) para reconocer e interpretar las diferentes formas y colores posibles con las que pueden venir las piezas.
\end{abstract}

Red neuronal artificial, Algoritmos, Segmentación de color, Extracción de características

Citation: CAMPAS-BUITIMEA, Julio, GONZÁLEZ-LÓPEZ, Samuel, MEDINA-MUÑOZ, Luis and RODRÍGUEZESPINOZA, Indelfonso. Model for identification of correct positioning of parts in a pick and place system. Journal of Technology and Innovation. 2019, 6-18: 1-4.

\footnotetext{
* Correspondence to Author (email: julio_kmpas@hotmail.com)

$\dagger$ Researcher contributing first author.
} 


\section{Introduction}

The need for identification technologies and classification of parts in the manufacturing process has become relevant in recent years as a result of greater demand for quality by customers. The recognition of pieces can also play an important role in the fields of monitoring and process management, avoiding the loss of capital due to poor quality production and long manufacturing time. The recognition process proposed in this document is based on the use of extraction techniques of specific characteristics of digital images. Different automatic learning algorithms are tested in the data set of 150 vehicle front view images (70 good parts for training, 30 bad parts for training) and experiments are carried out to evaluate their performance.

\section{Development}

The proposed model is based on the capture of images by means of a camera, in this image a pattern is recognized with which the image is normalized, after that recognized piece is extracted personalized characteristics to be compared by a neural network which is trained with images of good and bad pieces to finally give a trial. In Figure 1 we can see the structure of the proposed model:

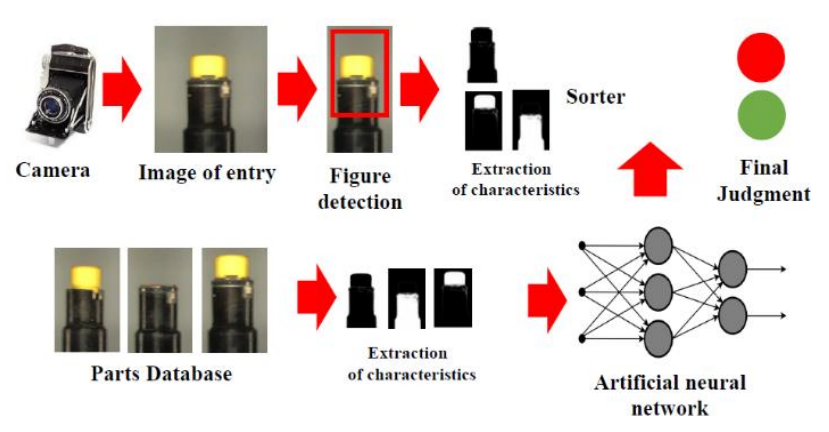

Figure 1 Proposed model structure

In the figure detection process, it is proposed to locate the region of interest (ROI) through the use of color segmentation algorithms. The camera will take an input image and the algorithm will detect a pattern of shapes which will cut out the region of interest to discard the rest of the photograph.

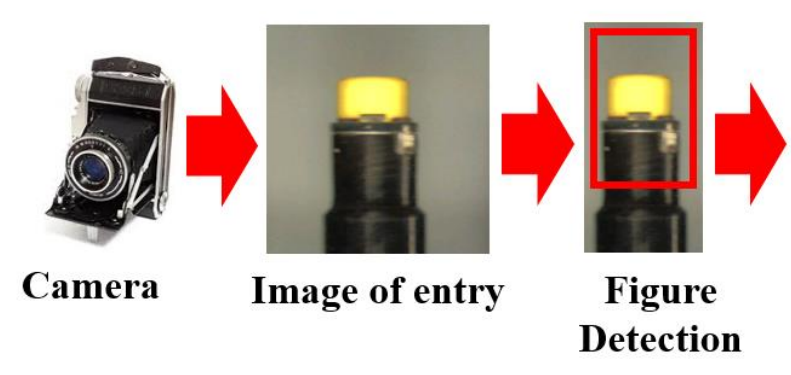

Figure 2 Detection process

Followed by this the model extracts from the remaining image three different images segmented by the same colors to obtain the characteristics of the image.

The algorithms proposed for this are:

Gaussian defocusing: performs $n$ individual 3D convolutions with Gaussian cores with the $n$ normal variations of sigma. The larger the radius, the more blurred the image will become until the pixels are homogeneous.

Gauss difference: calculates two fuzzy Gauss images of the original image and subtracts one from the other

Sobel filter: calculates an approximation of the gradient of the intensity of the image in each pixel. Gaussian defocuses with sigma varying as usual, are performed before the filter. From the original image the method will apply these algorithms for three different parts of the image.

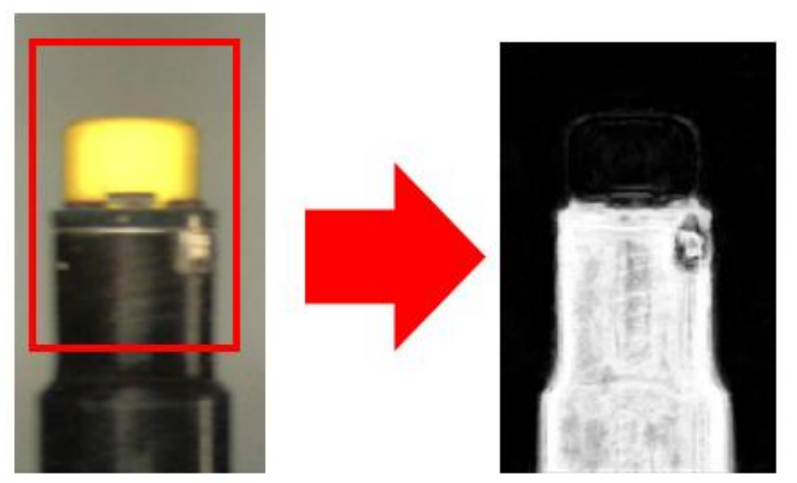

Figure 3 Image treatment

\section{Integration}

For the classification of good and bad parts, the use of a convolution neural network is proposed. For this system, the number of hidden neurons is set to 2. One trained for all the characteristics of a piece badly placed and another trained for all the characteristics of a well placed piece. 


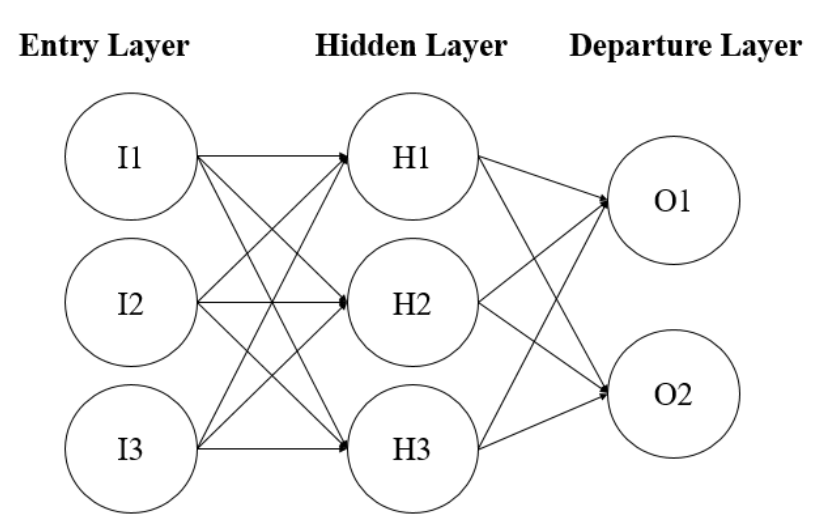

Figure 4 Neural network structure

All these algorithms were tested with the IMAGEJ program using the Weka Segmentation Trainable tool. This tool is used to segment the input image data (grayscale or 2D color), TWS transforms the segmentation problem into a pixel classification problem in which each pixel can be classified as belonging to a specific segment or class. A set of input pixels that has been tagged is represented in the space of the characteristic and then used as the training set for a selected classifier. Once the classifier is trained, it can be used to sort the rest of the input pixels or completely new image data. You can use all the available methods in WEKA.

\section{Tests}

The first image that results is the background highlighting in white, when applying the algorithms for this color the image remains blank for the whole background and in black for the rest.

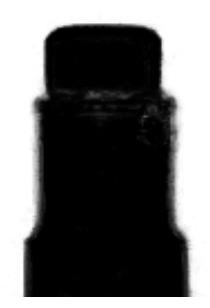

Figure 5 background classification

The second image this time with the algorithms trained with other colors highlights the pin where the pieces of interest are placed, in this case the color of the pin highlights in white and the rest remains in black.

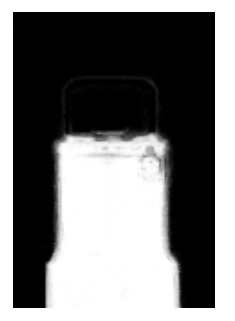

Figure 6 Pin classification

Finally, the same algorithms now trained to recognize the color of the good piece highlight the blank piece above all else.

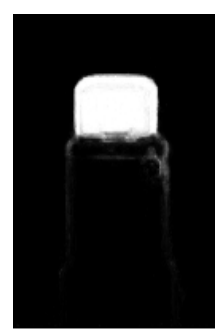

Figure 7 Classification of piece

100 images were collected. The results obtained were the following using a BayesNet classifier In percentage divided to $66 \%$. Therefore, only 44 instances were put to the test.

\begin{tabular}{|l|l|}
\hline Instances correctly classified & $97.72 \%$ \\
\hline Instances classified incorrectly & $2.27 \%$ \\
\hline
\end{tabular}

\section{Table 1 Results}

\section{Conclusions}

Thanks to the obtaining of characteristics and the contrast of colors it is quite marked to the neural network it is easier to classify the pieces between good or bad, in the proposed method there are only three characteristics that are proposed, but they can be more. As a method to detect presence or absence and color of dielectric is quite robust. With the results obtained, the neural network can be trained with these characteristics. The proposed model does not require a large investment, compared to the current vision systems and sensors of recognized brands.

\section{References}

De La Escalera, A.; Moreno, L.E.; Salichs, M.A.; Armingol, J.M. Road traffic sign detection and classification. IEEE Trans. Ind. Electr. 1997, 44, 848-859. [CrossRef] 
Deshmukh, V.R.; Patnaik, G.; Patil, M. Real-time traffic sign recognition system based on colour image segmentation. Int. J. Comput. Appl. 2013, 83. [CrossRef]

Mariut, F.; Fosalau, C.; Avila, M.; Petrisor, D. Detection and recognition of traffic signs using gabor filters. In Proceedings of the 2011 34th International Conference on Telecommunications and Signal Processing (Tsp), Budapest, Hungary, 18-20 August 2011; pp. 554-558.

Rizvi, R.; Kalra, S.; Gosalia, C.; Rahnamayan, S. Fuzzy adaptive cruise control system with speed sign detection capability. In Proceedings of the 2014 IEEE International Conference on Fuzzy Systems, Beijing

Shoba, E.; Suruliandi, A. Performance analysis on road sign detection, extraction and recognition techniques. In Proceedings of the 2013 International Conference on Circuits, Power and Computing Technologies (ICCPCT), Nagercoil, India, 20-21 March 2013; pp. 1167-1173.

Wu, J.; Si, M.; Tan, F.; Gu, C. Real-time automatic road sign detection. In Proceedings of the Fifth International Conference on Image and Graphics (ICIG'09), Xi'an, China, 20-23 September 2009; pp. 540-544.

Y. Nguwi and A. Kouzani, "Automatic road sign recognition using neural networks," in Proc. Int. Joint Conf. Neural Netw., Vancouver, BC, Canada, 2006, pp. 3955-3962.

Yamamoto, J.; Karungaru, S.; Terada, K. Japanese road signs recognition using neural networks. In Proceedings of the SICE Annual Conference, Nagoya, Japan, 14-17 September 2013; pp. 1144-1150.

Zhang, Q.S.; Kamata, S. Improved color barycenter model and its separation for road sign detection. IEICE Trans. Inf. Syst. 2013, E96D, 2839-2849. [CrossRef] 